\title{
Clinical Characteristics and Circulating Collagen and Laminin Metabolites in Insulin-Dependent Diabetic Children with Joint and Skin Manifestations
}

\author{
RIITTA VEIJOLA, MIKAEL KNIP, LEILA RISTELI, JUHA RISTELI, MARJA-LIISA KÄÄR, \\ RAIJA PUUKKA, AND JORMA ILONEN \\ Department of Pediatrics [R.V., M.K., M.-L.K.], Department of Medical Biochemistry [L.R., J.R.], Department of \\ Clinical Chemistry [R.P.], and Department of Medical Microbiology, University of Oulu, and National Public \\ Health Institute [J.I.], Oulu, Finland
}

\begin{abstract}
One hundred seventy-four children and adolescents with insulin-dependent diabetes mellitus were examined for joint contractures and skin manifestations in their hands. Joint contractures were found in $\mathbf{5 2}(\mathbf{2 9 . 8 \% )}$ and skin manifestations in $29(16.6 \%)$ patients. To eliminate the possible confounding effects of age and duration of diabetes on the variables to be studied, patients younger than $7 y$ and with a duration of diabetes shorter than $3 y$ were excluded from the subsequent analyses. Of the remaining 108 children, those with joint contractures had lower serum concentrations of the 7-S domain of type IV collagen and the P1 fragment of laminin than the other patients $(p=0.033)$ but higher mean glycated $\mathrm{Hb}$ levels $(p=0.048)$. A clear association was noted between the occurrence of joint contractures and skin changes $(p=$ 0.007). Background retinopathy was found in six patients $(5.6 \%)$, three of whom had stage II joint contractures ( $p$ $=0.064$ ). The children with skin changes and those with combined joint and skin manifestations more often had insulin-dependent diabetes mellitus in their first-degree relatives $(p=0.038$ and $p=0.043$, respectively). No difference in relative height was found between the groups. No association could be seen between disease susceptibility antigens in the HLA-D locus and joint or skin manifestations. The lower levels of circulating collagen and laminin metabolites in the diabetic children with joint contractures suggest that these patients are characterized by a reduced turnover of basement membranes in tissues. In addition, our data suggest that the development of joint contractures is associated with impaired metabolic control but not necessarily with growth retardation. (Pediatr Res 33: 501505,1993 )
\end{abstract}

\section{Abbreviations}

IDDM, insulin-dependent diabetes mellitus

$\mathrm{HbA}_{1 \mathrm{C}}$, hemoglobin $\mathrm{A}_{1 \mathrm{C}}$

IBA, insulin-binding antibody

PIINP, aminoterminal propeptide of type III procollagen CI, confidence interval

There have been a number of reports over the last $15 \mathrm{y}$ indicating that joint contractures and skin thickening, mainly

Received September 19, 1991; accepted December 17, 1992.

Correspondence: Dr. Mikael Knip, Department of Pediatrics, University of Oulu, SF-90220 Oulu, Finland.

Supported in part by Novo Research Institute, Bagsvaerd, Denmark. affecting the small joints of the hands, are common manifestations of IDDM in childhood and adolescence (1-10). The prevalence of joint contractures has varied from 8 to $50 \%$ (11), and skin manifestations have been reported to occur in 34 to $51 \%$ of children with $\operatorname{IDDM}(5,7,12)$ often in association with joint contractures $(3,8,12)$.

In many reports, the presence of joint contractures in diabetic patients has shown a positive correlation with the duration of the disease $(1,3,4,6-8,13)$ and the actual age of the patients $(1,2,4,7,10)$, which appears to be the most important variable in the expression of diabetic joint contractures (11). The association of joint contractures with growth retardation has remained controversial $(1,6,7,10,14)$. No correlation has been found between joint contractures and poor metabolic control in earlier reports $(1,3,4,6,10)$, but recently a positive association between elevated blood $\mathrm{HbA} 1$ levels and the presence of joint contractures has been described among adolescents and adults with IDDM (15). Furthermore, an increased risk of microvascular complications, such as retinopathy, has been observed in the presence of joint contractures $(3,8,9,12,13,15)$.

The etiology of the joint and skin manifestations is unknown. The collagen content of capillary basement membranes is increased in patients with $\operatorname{IDDM}(7,16,17)$, and it has been suggested that alterations in collagen structure, possibly related to glycation, may result in more stable forms $(7,18)$.

The aim of the present work was to determine the prevalence of joint and skin manifestations in an unselected series of diabetic children and adolescents and to identify factors associated with these changes, especially the possible relationship between serum concentrations of laminin and collagen metabolites and joint or skin manifestations.

\section{PATIENTS AND METHODS}

Patients. The series included 174 diabetic children and adolescents (102 boys) who visited the Diabetes Clinic at the Department of Pediatrics, University of Oulu, Oulu, Finland, in the course of $1 \mathrm{y}$. The mean age of the patients was $12.0(4.1 \mathrm{SD}) \mathrm{y}$ (range 3.1 to $21.9 \mathrm{y}$ ), and the mean duration of diabetes 5.2 (3.6 SD) y (range 0.1 to $16.5 \mathrm{y}$ ). Twenty-four patients (13.9\%) had one or more first-degree relatives with IDDM.

When analyzing the relationship between joint and skin manifestations and other factors, patients younger than $7 \mathrm{y}$ and with a duration of diabetes shorter than $3 y$ were excluded to eliminate the possible confounding effects of age and duration of the disease. The mean age of the remaining 108 patients was 13.6 
(3.0 SD) y (range 7.2 to $21.9 \mathrm{y}$ ), and the mean duration of diabetes 7.2 (3.1 SD) y (range 3.0 to $16.5 \mathrm{y}$ ).

Serum concentrations of laminin P1 and collagen metabolites were measured in 84 subjects who did not differ in their clinical characteristics from the larger group of 108 subjects.

Clinical methods. All patients were examined for joint and skin manifestations by the same observer (R.V.). The presence of joint contractures in the fingers was evaluated by the method described by Grgic et al. (1). The patient was asked to place his right hand on the tabletop palm down with fingers fanned, and the examiner determined the contact between the fingers and the plane surface by looking at table level. The entire palmar surface of the fingers should normally make contact. The patients were classified as having stage I contractures if they were unable to make contact with some portion of one finger and as having stage II contractures if they could not make contact with two or more fingers. Another method for demonstrating joint mobility in the fingers was to ask the patient to place his hands together in a praying position and to assess the ability to oppose the full palmar surfaces of the fingers (4). Again, the patients were classified as having stage I contractures if they were unable to make contact with some portion of one pair of fingers and as having stage II deformations if flexion contractures were seen in two or more pairs. Contractures were confirmed by the examiner's attempt to passively extend the fingers. If there was any discrepancy between these two methods, the patient was classified according to the milder finding. Skin changes in the hands were evaluated by palpation and inspection $(1,5)$. Skin thickening and induration were most readily discernible in terms of an inability of the examiner to grasp a fold over the dorsal surface of the proximal phalanges of the fingers.

The growth of the patients was monitored by means of height and weight measurements on every visit to the Diabetes Clinic. The height was measured with the same Harpenden stadiometer. The results were expressed in terms of relative height (SD score) and relative weight $(\%)$ by reference to Finnish growth charts (19).

A retinal examination through dilated pupils was performed by an ophthalmologist in a darkened room to detect early signs of microvascular complications of diabetes. The finding of one or more microaneurysms or red dot lesions was considered to indicate background retinopathy. No one was observed to have proliferative retinopathy.

Biochemical methods. Metabolic control of diabetes was assessed by the level of blood $\mathrm{HbA}_{1 \mathrm{C}}$, which was determined by ion-change chromatography using a method modified from that of Trivelli et al. (20) with a reference range of 4.1 to $6.3 \%$ in nondiabetic children.

Random serum C-peptide concentrations were measured with an RIA using antiserum M 1230 (Novo Research Institute, Bagsvaerd, Denmark), as previously described (21). The detection limit was $0.02 \mathrm{nmol} / \mathrm{L}$. IBA were assayed by a modification of the method described by Welborn et al. (22), using dextrancoated charcoal instead of ethanol precipitation to separate free and bound insulin. HLA-Dw typing was carried out with local homozygous typing cells (23).

Serum concentrations of the 7-S domain of type IV collagen and the laminin P1 fragment were measured using specific RIA with reference intervals for adults of 4.1 to $9.7 \mu \mathrm{g} / \mathrm{L}$ and 15 to $37 \mu \mathrm{g} / \mathrm{L}$, respectively (24). These reference values have been found to be independent of age in a study including children younger than 4 y (25) as well as among adults (24). Serum levels of PIIINP were quantified with a rapid equilibrium RIA (26). The reference intervals for PIIINP were 3.6 to $12.2 \mu \mathrm{g} / \mathrm{L}$ in 7 - to 10 -y-old children, 3.1 to $17.2 \mu \mathrm{g} / \mathrm{L}$ in 11 - to 13 -y-olds and 2.0 to $21.5 \mu \mathrm{g} / \mathrm{L}$ in $14-$ to $17-y$-olds. These measurements were performed on all available samples at the time of clinical examination. In addition, a second sample was obtained from a subgroup of 30 subjects after a mean interval of 9 mo (range 3 to $20 \mathrm{mo}$ ) to analyze the consistency of serum laminin and collagen metabolite levels.

Statistical methods. The data were evaluated statistically by means of cross-tabulation and $\chi^{2}$ statistics, $t$ test in the case of normally distributed variables, and the Mann-Whitney $U$ test in the case of an unequal distribution. Linear regression analysis was used to compare serum laminin and collagen metabolite levels at different time points.

\section{RESULTS}

Joint contractures were observed in 52 diabetic children and adolescents (29.8\%) in this cross-sectional survey $(95 \% \mathrm{CI}, 23.1$ to $36.7 \%)$, and 18 subjects $(10.3 \%)(95 \% \mathrm{CI}, 5.8$ to $14.9 \%)$ were classified as having stage II contractures. Skin manifestations were seen in 29 patients (16.6\%) (95\% CI, 11.1 to $22.2 \%$ ).

In the series including 108 subjects (age 7 y or more; duration of diabetes $3 \mathrm{y}$ or more) the prevalences for joint contractures and skin manifestations were $40.7 \%$ and $24.1 \%$, respectively (Table 1). The mean $\mathrm{HbA}_{1 \mathrm{C}}$ level was higher in those with joint contractures than in the others. There were no significant differences in sex distribution, age at diagnosis, circulating levels of IBA, or daily insulin dose between the two groups. The relative height and weight were of the same magnitude in both groups, and no significant difference was found in relative height between those with stage II contractures $(n=17)$ and other patients. Background retinopathy was found in six patients $(5.6 \%)(95 \%$ CI, 1.2 to $9.9 \%$ ), three of whom had stage II joint contractures. The association between more severe joint manifestations and background retinopathy was not significant ( $p=0.064)$.

The patients with skin manifestations more often had firstdegree relatives with IDDM than those without skin manifestations (Table 2). Similarly, six (35.3\%) patients out of 17 having both joint and skin manifestations ( $95 \% \mathrm{CI}, 12.6$ to $58.0 \%)$ had IDDM in their first-degree relatives, compared with $11(12.2 \%)$ out of the remaining 90 patients $(95 \% \mathrm{CI}, 5.5$ to $19.0 \% ; p=$ 0.043 ). We did not find any significant differences in $\mathrm{HbA}_{1 \mathrm{C}}$ level or relative height between those with skin manifestations and those without. Joint contractures were observed in 17 patients $(65.4 \%)$ with skin manifestations as compared with 27 $(32.9 \%)$ without skin changes $(p=0.007)$. Disease susceptibility antigens were detected in the HLA-D locus as often in those with joint or skin manifestations as in the other diabetic children.

Serum concentrations of $7-S$ collagen and laminin $\mathrm{Pl}$ were lower in the patients with joint contractures than in those without contractures (Table 3 ). No difference was found in the serum levels of 7-S collagen, PIIINP, and laminin P1 between the skin manifestation group and the other patients (Table 4). The consistencies of serum laminin P1, 7-S collagen, and PIIINP concentrations over a period of 9 mo (range 3 to $20 \mathrm{mo}$ ) were good $(r$ $=0.79$ for serum laminin P1, $r=0.76$ for 7 -S collagen, and $r=$ 0.82 for PIIINP concentrations; $p<0.001$ for all three analyses).

\section{DISCUSSION}

The prevalence of joint contractures in diabetic children found in this study, $29.8 \%$, is similar to figures reported previously (1, $3,6,11)$. Thick, tight, waxy skin was often seen in association with these joint contractures, although the prevalence of the skin manifestations $(16.6 \%)$ was lower than in previous reports $(5,7$, 12). This may be because evaluation of the skin is subjective and accordingly prone to considerable interobserver variation. In the series of 108 subjects, the prevalences for both joint contractures and skin manifestations were higher because older subjects with longer duration of IDDM were included in this subgroup.

Other authors have failed to find any association between metabolic control and joint contractures in diabetic children (1, $3,4,6,10)$. Our observations suggest, however, that impaired metabolic control may be related to the development of joint and skin manifestations, inasmuch as the mean level of $\mathrm{HbA}_{1 \mathrm{C}}$ 
Table 1. Clinical and laboratory data for 108 diabetic children and adolescents with and without joint contractures*

\begin{tabular}{|c|c|c|c|}
\hline & \multicolumn{2}{|c|}{ Joint contractures } & \multirow{2}{*}{$\begin{array}{l}\text { Significance of } \\
\text { difference }\end{array}$} \\
\hline & $+(n=44)$ & $-(n=64)$ & \\
\hline Sex (male/female) & $23 / 21$ & $38 / 26$ & NS \\
\hline Age $(y)$ & $14.1(13.4-14.8)$ & $13.3(12.4-14.1)$ & NS \\
\hline Age at diagnosis $(\mathrm{y})$ & $6.5(5.6-7.4)$ & $6.4(5.5-7.3)$ & NS \\
\hline Duration of diabetes $(y)$ & $7.6(6.7-8.5)$ & $6.9(6.1-7.7)$ & NS \\
\hline IDDM in first-degree relatives, prevalence (\%) & $20.9(8.8-33.1)$ & $12.5(4.4-20.6)$ & NS \\
\hline Relative height (SD-score) & $-0.5(-0.8--0.3)$ & $-0.6(-0.8--0.4)$ & NS \\
\hline Relative weight (\%) & $104.5(101.4-107.5)$ & $102.3(99.8-104.8)$ & NS \\
\hline Daily insulin dose (U/kg) & $0.69(0.66-0.72)$ & $0.69(0.65-0.73)$ & NS \\
\hline Detectable serum C-peptide, prevalence (\%) & $11.6(2.1-21.1)$ & $13.1(4.8-21.4)$ & NS \\
\hline $\mathrm{HbA}_{1 \mathrm{C}}(\%)$ & $12.3(11.5-13.1)$ & $11.2(10.6-11.9)$ & $p=0.048$ \\
\hline $\operatorname{IBA}(\%)$ & $5.0(1.7-8.2)$ & $11.2(6.6-15.8)$ & NS \\
\hline Dw3, prevalence $(\%)$ & $18.2(6.8-29.6)$ & $15.6(6.7-24.5)$ & NS \\
\hline Dw4, prevalence $(\%)$ & $47.7(33.0-62.5)$ & $40.6(28.6-52.7)$ & NS \\
\hline Dw3/Dw4, prevalence (\%) & $11.4(2.0-20.7)$ & $15.6(6.7-24.5)$ & NS \\
\hline Skin changes, prevalence $(\%)$ & $38.6(24.2-53.0)$ & $14.1(5.5-22.6)$ & $p=0.007$ \\
\hline Retinopathy, prevalence $(\%)$ & $7.1(0.0-14.9)$ & $4.8(0.0-10.0)$ & NS \\
\hline
\end{tabular}

* Values are means or prevalences $(95 \% \mathrm{CI})$. Subjects were age $7 \mathrm{y}$ or more with a duration of diabetes of $3 \mathrm{y}$ or more.

Table 2. Clinical and laboratory data for 108 diabetic children and adolescents with and without skin manifestations*

\begin{tabular}{|c|c|c|c|}
\hline & \multicolumn{2}{|c|}{ Skin manifestation } & \multirow{2}{*}{$\begin{array}{l}\text { Significance of } \\
\text { difference }\end{array}$} \\
\hline & $+(n=26)$ & $-(n=82)$ & \\
\hline Sex (male/female) & $16 / 10$ & $45 / 37$ & NS \\
\hline Age $(y)$ & $13.9(13.1-14.8)$ & $13.5(12.8-14.2)$ & NS \\
\hline Age at diagnosis (y) & $6.7(5.7-7.6)$ & $6.4(5.6-7.1)$ & NS \\
\hline Duration of diabetes $(y)$ & $7.3(6.1-8.4)$ & $7.1(6.4-7.8)$ & NS \\
\hline IDDM in first-degree relatives, prevalence (\%) & $30.8(13.0-48.5)$ & $11.1(4.3-18.0)$ & $p=0.038$ \\
\hline Relative height (SD score) & $-0.6(-1.1--0.2)$ & $-0.6(-0.8--0.4)$ & NS \\
\hline Relative weight (\%) & $102.7(98.9-106.6)$ & $103.3(101.1-105.6)$ & NS \\
\hline Daily insulin dose $(\mathrm{U} / \mathrm{kg})$ & $0.71(0.66-0.76)$ & $0.68(0.65-0.71)$ & NS \\
\hline Detectable serum C-peptide, prevalence (\%) & $12.0(0.0-24.7)$ & $12.7(5.3-20.0)$ & NS \\
\hline $\mathrm{HbA}_{1 \mathrm{C}}(\%)$ & $12.1(11.1-13.0)$ & $11.6(10.9-12.2)$ & NS \\
\hline $\operatorname{IBA}(\%)$ & $7.2(0.5-13.9)$ & $9.6(5.8-13.4)$ & NS \\
\hline Dw3, prevalence (\%) & $23.1(6.9-39.3)$ & $13.4(6.0-20.8)$ & NS \\
\hline Dw4, prevalence $(\%)$ & $34.6(16.3-52.9)$ & $46.3(35.5-57.1)$ & NS \\
\hline Dw3/Dw4, prevalence (\%) & $19.2(4.1-34.4)$ & $12.2(5.1-19.3)$ & NS \\
\hline Joint contractures, prevalence $(\%)$ & $65.4(47.1-83.7)$ & $32.9(22.8-43.1)$ & $p=0.007$ \\
\hline Retinopathy, prevalence (\%) & $4.0(0.0-11.7)$ & $6.3(0.9-11.6)$ & NS \\
\hline
\end{tabular}

* Values are means or prevalences $(95 \% \mathrm{CI})$. Subjects were age $7 \mathrm{y}$ or more with a duration of diabetes of $3 \mathrm{y}$ or more.

Table 3. Serum concentrations of laminin PI and collagen metabolites for diabetic children and adolescents with and without joint contractures*

\begin{tabular}{lccc}
\hline & \multicolumn{2}{c}{ Joint contractures } & \multicolumn{2}{c}{$\begin{array}{c}\text { Significance of } \\
\text { difference }\end{array}$} \\
\cline { 2 - 4 } & $+(n=34)$ & $-(n=50)$ & $p=0.033$ \\
Serum laminin P1 $(\mu \mathrm{g} / \mathrm{L})$ & $28.6(25.8-31.4)$ & $35.9(30.7-41.2)$ & $p=0.033$ \\
Serum 7-S collagen $(\mu \mathrm{g} / \mathrm{L})$ & $5.5(5.1-5.9)$ & $6.2(5.8-6.5)$ & $\mathrm{NS}$ \\
Serum PIINP $(\mu \mathrm{g} / \mathrm{L})$ & $7.1(6.2-7.9)$ & $7.8(7.2-8.5)$ & $\mathrm{N}$ \\
\hline
\end{tabular}

* Values are means $(95 \% \mathrm{CI})$. Subjects were age $7 \mathrm{y}$ or more with a duration of diabetes of $3 \mathrm{y}$ or more.

Table 4. Serum concentrations of laminin PI and collagen metabolites for diabetic children and adolescents with and without skin manifestations*

\begin{tabular}{lccc}
\hline & \multicolumn{2}{c}{ Skin manifestations } & \multicolumn{2}{c}{$\begin{array}{c}\text { Significance of } \\
\text { difference }\end{array}$} \\
\cline { 2 - 3 } & $+(n=22)$ & $-(n=62)$ & NS \\
Serum laminin P1 $(\mu \mathrm{g} / \mathrm{L})$ & $31.9(25.4-38.4)$ & $33.3(29.3-37.2)$ & NS \\
Serum 7-S collagen $(\mu \mathrm{g} / \mathrm{L})$ & $5.9(5.4-6.4)$ & $5.9(5.6-6.3)$ & NS \\
Serum PIIINP $(\mu \mathrm{g} / \mathrm{L})$ & $7.3(6.2-8.3)$ & $7.6(7.0-8.2)$ & \\
\hline
\end{tabular}

\footnotetext{
* Values are means $(95 \% \mathrm{CI})$. Subjects were age 7 or more with a duration of diabetes of $3 \mathrm{y}$ or more.
} 
was higher in the presence of joint contractures even after exclusion of the confounding effects of age and duration of diabetes.

The initial investigations into this topic described growth retardation in association with severe joint contractures $(1,14)$. More recently, in a survey including 142 patients with diabetes, presumably diagnosed before puberty, and a duration of diabetes longer than $3 \mathrm{y}$, Rosenbloom et al. (10) found that subnormal statural growth was associated with both mild and severe joint contractures but was also present in diabetic patients without joint manifestations. No statistical evaluation was included, however, to verify the association between joint contractures and growth retardation. We could not find any association between the relative height of the diabetic patients and the presence of joint or skin manifestations, nor could Starkman and Brink (6) in their examinations of 100 diabetic children in which patients with and without joint contractures were matched for age and duration of diabetes.

Our results, which showed no relationship between the frequency of disease susceptibility antigens in the HLA-D locus and joint or skin manifestations in IDDM, are in agreement with previous findings $(27,28)$. The fact that a positive family history of IDDM was noted more often in the patients with concurrent skin and joint manifestations or isolated skin manifestations has not been reported previously and indicates that unidentified genetic factors may be involved in the development of diabetic joint contractures and skin changes.

The fact that we could not find any difference in the levels of insulin binding antibodies between the patients with and without joint contractures does not support previous suggestions that circulating insulin antibodies may contribute to the development of chronic complications of diabetes $(29,30)$. The possible role of immune complexes in the pathogenesis of diabetic joint and skin manifestations remains to be investigated.

Thickening of the capillary basement membranes is a characteristic lesion in long-term diabetes and is considered to play a role in the pathogenesis of diabetic microangiopathy $(16,31)$. The total amount of collagen in basement membranes is known to increase in diabetes $(7,16,17)$, and decreased acid solubility, increased resistance to enzymatic degradation, and increased nonenzymatic glycation of skin and tendon collagen have been reported in patients with IDDM $(7,32-34)$. Accordingly, it has been suggested that these changes may lead to increased stability and accumulation of collagen in various tissues all over the body, which may contribute to the development of microangiopathic complications $(7,32)$.

Basement membranes contain both collagenous (type IV) and noncollagenous proteins. An aminoterminal crosslinking part of the type IV collagen molecule is known as the 7-S domain, whereas the main noncollagenous glycoprotein characterized in basement membranes is laminin, which comprises several antigenic determinants. Quantification of the circulating concentrations of these antigens can provide useful information on the metabolism of basement membranes. Serum concentrations of 7-S collagen and the laminin fragment P2 have been shown to increase in streptozotocin-induced diabetic rats, the former effect being inhibited by insulin treatment (35). Increased serum levels of the laminin fragment $\mathrm{P} 1$ have been found in adult patients with IDDM as compared with healthy persons, but no significant differences have been observed between type 1 diabetic patients with and without established microangiopathy (36). The serum concentration of PIIINP has been used as an indicator of the metabolism of interstitial collagens (37).

In the light of previous results, increased serum levels of laminin P1, 7-S collagen, and PIIINP could have been expected among the diabetic patients with joint and skin manifestations, but the results showed lower concentrations in the presence of joint contractures. Thus, we could not find any sign of accelerated collagen synthesis. In contrast, our observations do suggest a reduced turnover in basement membranes and interstitial tissues. This finding is in line with the hypothesis that the stability of collagens could be increased in the presence of joint and skin manifestations of diabetes.

The correlation between joint and skin manifestations and the degree of nonenzymatic glycation of skin collagen in diabetic patients has been investigated with conflicting results $(7,33,34$, 38 ), whereas no clear association has been found between the level of glycated $\mathrm{Hb}$ and these chronic complications of diabetes $(7,33)$. The present results showed a significant increase in $\mathrm{HbA}_{1 \mathrm{C}}$ in children with joint manifestations, and, accordingly, it seems logical that because metabolic control is impaired the nonenzymatic glycation of interstitial and basement membrane collagens could also be accelerated, leading to increased stability of collagen and its accumulation in various tissues.

Joint and skin manifestations are common complications of IDDM in childhood. The present findings suggest that the development of diabetic joint contractures is associated with lower serum concentrations of collagen and laminin metabolites. Our data also indicate that joint manifestations are associated with impaired metabolic control in diabetic children. The development of joint and skin manifestations seems to be unrelated to known genetic markers of IDDM because we could not find any association between the disease susceptibility antigens in the HLA-D locus and the presence of such manifestations. On the other hand, the overrepresentation of familial cases with IDDM among the patients with both joint and skin manifestations implies that genetic factors unrelated to the HLA system may play a role in the pathogenesis of these diabetic complications.

Acknowledgments. The authors thank Sirkka Länkelä, R.N., for assistance in the recruitment of the patients and Aila Utoslahti for expert technical assistance.

\section{REFERENCES}

1. Grgic A, Rosenbloom AL, Weber FT, Giordano B, Malone JI, Shuster JJ 1976 Joint contracture: common manifestation of childhood diabetes mellitus. J Pediatr 88:584-588

2. Traisman HS, Traisman ES, Marr TJ, Wise J 1978 Joint contractures in patients with juvenile diabetes and their siblings. Diabetes Care 1:360-361

3. Rosenbloom AL, Silverstein JH, Lezotte DC, Richardson K, McCallum M 1981 Limited joint mobility in childhood diabetes mellitus indicates increased risk for microvascular disease. N Engl J Med 305:191-194

4. Brice JEH, Johnston DI, Noronha JL 1982 Limited finger joint mobility in diabetes. Arch Dis Child 12:879-881

5. Seibold JR 1982 Digital sclerosis in children with insulin-dependent diabetes mellitus. Arth Rheum 25:1357-1361

6. Starkman H, Brink S 1982 Limited joint mobility of the hand in type 1 diabetes mellitus. Diabetes Care 5:534-536

7. Buckingham BA, Uitto J, Sandborg C, Keens T, Roe T, Costin G, Kaufman F, Bernstein B, Landing B, Castellano A 1984 Scleroderma-like changes in insulin-dependent diabetes mellitus: clinical and biochemical studies. Diabetes Care 7:163-169

8. Costello PB, Tambar PK, Green FA 1984 The prevalence and possible prognostic importance of arthropathy in childhood diabetes. J Rheumatol 11:6265

9. Madacsy L 1987 Joint and pulmonary changes in diabetes. Am J Dis Child 141:244-245

10. Rosenbloom AL, Silverstein JH, Lezotte DC, Riley WJ, Maclaren NK 1982 Limited joint mobility in diabetes mellitus of childhood: natural history and relationship to growth impairment. J Pediatr 101:874-878

11. Rosenbloom AL 1990 Limited joint mobility in insulin dependent childhood diabetes. Eur J Pediatr 149:380-388

12. Buckingham B, Perejda AJ, Sandborg C, Kershnar AK, Uitto J 1986 Skin, joint and pulmonary changes in type 1 diabetes mellitus. Am J Dis Child 40:420-423

13. Kennedy L, Beacom R, Archer DB, Carson DJ, Campbell SL, Johnston PB, Maguire CJ 1982 Limited joint mobility in type 1 diabetes mellitus. Postgrad Med J 58:481-484

14. Rosenbloom AL, Frias JL 1974 Diabetes mellitus, short stature and joint stiffness: a new syndrome. Clin Res 22:92A (abstr)

15. Garg SK, Chase PH, Marshall G, Jackson WE, Holmes D, Hoops S, Harris S 1992 Limited joint mobility in subjects with insulin-dependent diabetes mellitus: relationship with eye and kidney complications. Arch Dis Child 67:96-99

16. Risteli L, Risteli J 1988 Basement membrane related protein antigens in blood. In: Gubler MC, Sternberg M (eds) Progress in Basement Membrane Research. Renal and Related Aspects in Health and Disease. John Libbey Eurotext, London, pp 299-308

17. Klein L, Butcher DL, Sudilovsky O, Kikkawa R, Miller M 1975 Quantification 
of collagen in renal glomeruli isolated from human nondiabetic and diabetic kidneys. Diabetes 24:1057-1065

18. Knowles HB 1981 Joint contractures, waxy skin and control of diabetes. $N$ Engl J Med 305:217-219

19. Sorva R, Perheentupa J, Tolppanen EM 1984 A novel format for a growth chart. Acta Paediatr Scand 73:527-529

20. Trivelli LA, Ranney HM, Lai T 1971 Hemoglobin components in patients with diabetes mellitus. N Engl J Med 284:353-357

21. Heding LG 1975 Radioimmunological determination of human C-peptide in serum. Diabetologia 11:541-548

22. Welborn TA, Richards R, Fraser TR 1967 Simple test for insulin antibodies in sera using ${ }^{131}{ }^{1}$-insulin and ethanol precipitation. Br Med J 1:719-722

23. Ilonen J, Reunanen M, Salmi A, Tiilikainen A 1981 Lymphocyte blast transformation responses and viral antibodies in relation to HLA antigens in multiple sclerosis. J Neurol Sci 49:117-133

24. Niemelä O, Risteli L, Sotaniemi EA, Risteli J 1985 Type IV collagen and laminin-related antigens in human serum in alcoholic liver disease. Eur $\mathrm{J}$ Clin Invest 15:132-137

25. Trivedi P, Risteli J, Risteli L, Tanner MS, Bhave S, Pandit AN, Mowat AP 1987 Serum type III procollagen and basement membrane proteins as noninvasive markers of hepatic pathology in Indian childhood cirrhosis. Hepatology 7:1249-1253

26. Risteli J, Niemi S, Trivedi P, Mäentausta O, Mowat AP, Risteli L 1988 Rapid equilibrium radioimmunoassay for the aminoterminal propeptide of human type III procollagen. Clin Chem 34:715-718

27. Beacom R, Gillespie EL, Middleton D, Sawhney B, Kennedy L 1985 Limited joint mobility in insulin-dependent diabetes: relationship to retinopathy, peripheral nerve function and HLA status. Quart J Med 56:337-344
28. Rosenbloom AL, Silverstein JH, Riley WJ, Maclaren NK 1983 Limited joint mobility in childhood diabetes: family studies. Diabetes Care 6:370-373

29. Andersen OO, Egeberg J 1977 The clinical significance of insulin antibodies. Acta Paediatr Scand [Suppl] 270:63-68

30. Van Haeften TW 1989 Clinical significance of insulin antibodies in insulintreated diabetic patients. Diabetes Care 12:641-648

31. Kilo C, Vogler N, Williamson JR 1972 Muscle capillary basement membrane changes related to aging and to diabetes mellitus. Diabetes 21:881-905

32. Kohn RR, Schnider SL 1982 Glucosylation of human collagen. Diabetes 31(suppl 3):47-51

33. Salmela PI, Oikarinen A, Pirttiaho H, Knip M, Niemi M, Ryhänen L 1989 Increased non-enzymatic glycosylation and reduced solubility of skin collagen in insulin-dependent diabetic patients. Diabetes Res 11:115-120

34. Monnier VM, Viswanath V, Frank KE, Elmets CA, Dauchot P, Kohn RR 1986 Relation between complications of type 1 diabetes mellitus and collagen-linked fluorescence. N Engl J Med 314:403-408

35. Risteli J, Draeger KE, Regitz G, Neubauer HP 1982 Increase in circulating basement membrane antigens in diabetic rats and effects of insulin treatment. Diabetologia 23:266-269

36. Hasslacher C, Brocks DG 1986 Serum concentration of laminin in type diabetic patients with and without microangiopathy. Transplant Proc 18:1534

37. Risteli J, Risteli L 1989 Markers of collagen assembly and turnover. In: Lindh E, Thorell JI (eds) Clinical Impact of Bone and Connective Tissue Markers. Academic Press, London, pp 201-209

38. Lyons TJ, Kennedy L 1985 Non-enzymatic glycosylation of skin collagen in patients with type 1 (insulin-dependent) diabetes mellitus and limited joint mobility. Diabetologia 28:2-5 